\title{
Medical waste management during coronavirus disease 2019 pandemic at the city level
}

\author{
E. G. Polat ${ }^{1}$ (D)
}

Received: 10 December 2020 / Revised: 12 September 2021 / Accepted: 16 October 2021 / Published online: 26 October 2021

(C) Islamic Azad University (IAU) 2021

\begin{abstract}
Coronavirus disease 2019 brings about the economic damage and loss of life. Thus, demand of personal protective equipment continues to increase, consequently an increase in infectious equipment pollution. Most of these wastes threaten the environment and increase the spread of diseases. This paper provides a research hypothesis whether effective medical waste management would prevent the possible impacts of coronavirus disease 2019-related waste issues on environment at the city level. To confirm this hypothesis, installation of waste treatment centre is addressed. Then, by incorporating uncertain waste generation amounts utilizing Jimenez method, a pickup routing is addressed to decide the pickup routes between the waste treatment centre and residential area. This study is first to assign the optimistic, realistic and pessimistic scenarios of the uncertain waste generation using time series analysis method and waste generation formulation. Also, L-type matrix is used to define, assess and prioritize the environmental and operational risks on waste generation formulation and to provide risk reaction strategies. Practicality of these approaches is illustrated in the case of Turkey. The computational results reveal the effectiveness of the integrated method, which ensures practical and theoretical insights controlling the waste generation to prevent virus propagation for health authorities.
\end{abstract}

Keyword Epidemic outbreaks $\cdot$ Medical waste $\cdot$ Risk approach $\cdot$ Uncertain environment $\cdot$ Waste generation

\section{Introduction}

Coronavirus disease 2019 (COVID-19) has spread across the globe; thus, mortality rates have been increased (WHO, 2020). COVID-19 also brings about the change in waste generation and composition, disposal and waste management on waste process (Van Fan et al. 2020). Waste management sector consisting of waste production, waste treatment and disposal and challenges to the industry (Haque et al. 2020) is also affected. Personal protective equipment (PPE) is a good option for protecting medical workers and public against COVID-19 (Cook 2020) because COVID-19 has unknown characteristics and the solution is time-consuming and costly. Protective materials can be divided into two groups: protective materials (gowns, gloves, medical mask

Editorial Responsibility: Samareh Mirkia.

E. G. Polat

elifcangocmen@munzur.edu.tr

1 Department of Industrial Engineering, Munzur University, Tunceli, Turkey and face shield) used by health care professionals dealing with direct care of patients and medical masks for people who experience respiratory symptoms. The most critical issues confronting people are the alarming shortage and wastage of PPE. Medical equipment such as mask, glove and other tools should be available for all people in the epidemic outbreaks. Shortage of medical supplies can boost the death rate and cause the severe losses of the human lives (Govindan et al. 2020). An increasing demand for medical equipment (Kargar et al. 2020) is directly linked with the medical waste. The use of PPEs increases both the amount and density of the medical waste (Singh et al. 2020a, b). The pandemic management involves the fulfilment of preparation before disaster or after disaster to mitigate the negative impacts. Medical wastes produced during the COVID-19 have gained increasing attention (Yang et al. 2020). PPE, mask, glove and face shield bring about the huge contribution to waste amount (Ilyas et al. 2020). The coronavirus also remains on materials for days (Nzediegwu and Chang 2020). Therefore, an optimal management of PPE is important to control the outbreak. Infectious personal protective equipment (IPPE) should be organized with the measures linked 
with collection, treatment and burial to mitigate all risks (Korkut 2018). Medical waste such as contaminated mask and glove, called as hazardous waste, should be separated from the domestic waste (Zambrano-Monserrate et al. 2020). Since huge demand for protective material is predicted to boost suddenly in Turkey, medical waste will increase suddenly. Eco-friendly alternatives to enhance effective waste management system can ensure a sustainable world (Fadare and Okoffo 2020). The contribution of this paper is the demonstration of effective waste management system including location and routing decisions in IPPE management under uncertain environment. In addition, although three scenarios of the fuzzy parameters are allocated based on the historical data in the Jimenez method, Holt-Winters (HW) model and waste generation (WG) formulation is used to assign these scenarios, which is the scientific novelty in the presented paper. For WG formulation, most influential risks on IPPE waste generation are evaluated to provide risk reaction strategies. Also, in the second stage, both the mathematical modelling approach and the heuristics developed are used to compare the results. As far as we know, this presented study is first to provide the integrated IPPE waste treatment centre (WTC) location and pickup routing problem (PRP) considering prediction of uncertain waste amount. The main aims of the presented study are determination of the WTC location, solving pickup routing problem regarding uncertain waste amount, forecasting the uncertain WG, and determination of the most influential risks on IPPE waste generation, to provide risk reaction strategies utilizing the WG outcomes.

COVID-19 effects based on waste management are studied by various researchers (Penteado and Castro 2021). In this section, preliminary works related to this paper are presented to show the research gaps. Up to date, some studies related to the novel coronavirus are conducted, but generally in the medical subjects. Infectious medical waste for the COVID-19 pandemic was studied by $\mathrm{Yu}$ et al. (2020) and Kargar et al. (2020). However, many papers have been carried out related to the reverse logistics problems, but for a pandemic outbreak, to our knowledge, no papers have provided a framework related to IPPE waste management. Yu et al. (2020) presented mathematical modelling in a reverse logistics for medical waste in the COVID-19 pandemic. They decided some optimum locations and transportation planning. Budak and Ustundag (2017) addressed mixed integer modelling to decide some location decisions aiming at minimum cost. Their study covered the pickup, distribution and disposition of medical waste. Liu et al. (2020) used a heuristic to determine the waste storage placement. Also, transportation modelling for medical waste between hospital and storage placements was developed with the ant colony-tabu hybrid algorithms. Mantzaras and Voundrias (2017) addressed a model that decides the waste treatment locations, waste volume, distribution vehicles and vehicle routes. They used two software applications to solve this problem and observe that major share of the cost is related to the treatment installation cost. Nolz et al. (2014) presented a mathematical formulation for the stochastic IRP considering pickup of medical waste, mitigation of medical risk, etc. Heuristic solutions were also provided for methods on real-world study. Chauhan and Singh (2016) provided health care waste disposal location problem utilizing multi-criteria decision-making (MCDM) methods. Yazdani et al. (2020) and Gergin et al. (2019) addressed a waste disposal location problem using a new best-worst method and a clustering algorithm, respectively.

Medical waste research is mainly carried out using MCDM methods. Decision on the optimal waste treatment methods was grouped under MCDM problems by Zavadskas et al. (2016) and Iglesias et al. (2008). Liu et al. (2013) presented a MCDM method including fuzzy approach to assess medical waste disposal techniques. They considered various options such as incineration and steam sterilization. Liu et al. (2015) provided a MCDM method to choose the health care waste treatment options. Dursun et al. (2011) developed a MCDM method based on fuzzy logic to select the medical waste treatment options. Mishra et al. (2020) addressed a MCDM problem of health care waste disposal methods utilizing evaluation based on distance from average solution (EDAS). Steam sterilization was selected as the optimal medical waste disposal technique. Ju et al. (2020) also presented a selection problem of medical waste disposal method using multi-granular linguistic distribution assessments (LDA). They obtained the steam sterilization as the most optimal medical waste disposal technique. Xiao (2018) developed a new MCDM tool to assess the optimal treatment technology for the health care waste. D numbers were used to deal with human judgement due to the various uncertainties. Steam sterilization was provided as the optimal technology to handle this waste. Makajic-Nikolic et al. (2016) developed a fault tree analysis (FTA) to evaluate the risks evaluation of health care waste. The highest scored failures were determined, and measures to prevent the failures are provided in medical waste management.

Preliminary papers are provided to reveal the gaps in the literature. Up to date, some studies related to the novel coronavirus are conducted, but generally in the medicine area. As far as we know, considering theoretical view, this study is first to present the integrated IPPE waste management decisions considering uncertain WG. Regarding practical gap, a real-world case is addressed to demonstrate the developed model at the city level.

This work was conducted in 2020, in the University of Munzur, Tunceli, Turkey. 


\section{Materials and methods}

Efficient waste management is one of the main milestones of sustainable world. In recent years, sustainability and ecological concerns regarding waste issues have shown a substantial increase due to global warming, epidemic disasters, and natural disasters. Thus, waste-based methods are hot research topics for both practitioners and researchers. Waste solutions incorporating minimization and prevention issues are popular in the waste management area. To make these decisions scientific sound, integrated solution approaches should be carried out. Thus, a combined problem including location and PRP regarding uncertain WG is proposed in this paper. Figure 1 depicts a representation of two stages of presented problem. In the first stage, location problem regarding demand-weighted distances and installation costs is solved. In the second stage, routes are decided between the installed WTC and residential areas. In this stage, picked-up waste amounts are uncertain. Thus, Jimenez method is carried out in the second stage. This method uses optimistic, realistic and pessimistic scenarios. For these scenarios, two methods are used to predict the WG.

Amount of IPPE waste has significantly increased during the COVID-19 (Rhee 2020). More than 240 tons of medical waste (mask, gloves) is observed per day (Adyel 2020). The type of PPE wastes can include glove, medical mask, goggle, shield, gown, respirator and apron (WHO 2020). The major share related to the type of wastes is mainly observed as masks since the widely used PPE is face masks (Dargaville et al. 2020). Medical waste amount between 2009 and 2019 is represented in Table 1 that provides an increasing pattern of the medical waste amount until 2015. In 2015, the high value is obtained, and then a decreasing pattern is observed. This year is expected as high value due to the outbreak.

To investigate the impacts of the environment and operation risks on WG formulation for medical facilities and residential area, environmental risks including high infection rate, increasing population, mortality rate, recovery rate, PPE costs and insufficient budget for waste measures, and operational

Table 1 Medical waste amount between 2009 and 2019 (Tunceli Province 2019 Environmental Status Report)

\begin{tabular}{lll}
\hline Year & Time period (t) & $\begin{array}{l}\text { Medical waste } \\
\text { amount (tonne) }\end{array}$ \\
\hline 2009 & 1 & 29,4 \\
2010 & 2 & 28,02 \\
2011 & 3 & 24,9 \\
2012 & 4 & 42,54 \\
2013 & 5 & 43,22 \\
2014 & 6 & 74,52 \\
2015 & 7 & 248,396 \\
2016 & 8 & 52,85 \\
2017 & 9 & 52,654 \\
2018 & 10 & 54,778 \\
2019 & 11 & 61,015 \\
\hline
\end{tabular}

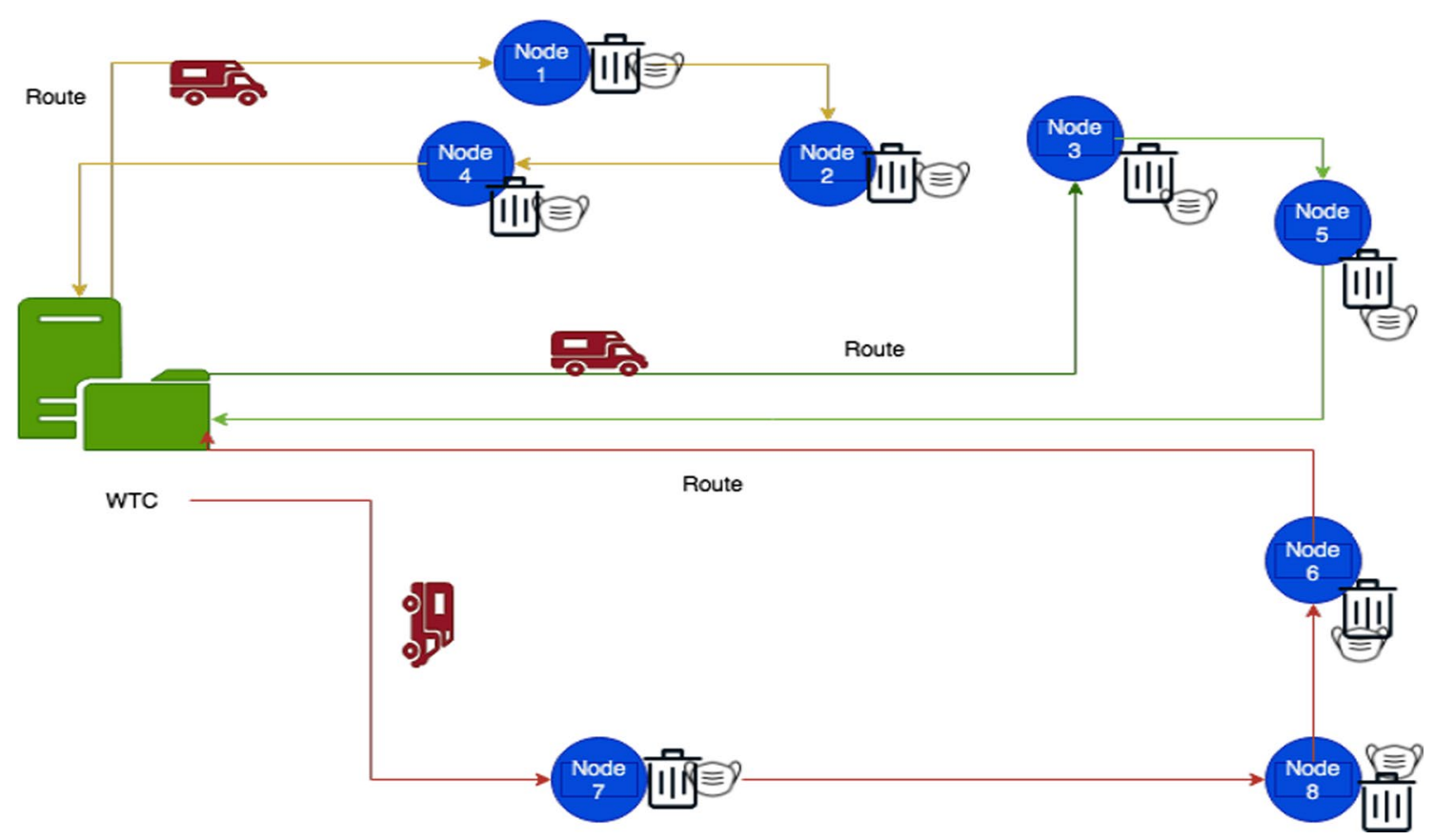

Fig. 1 A representation of the proposed problem 
risks including low recyclability rate of PPE, high disposal costs, high maintenance costs, lack of waste workers and lack of control in waste WTCs are defined. Thus, optimal risk reaction strategies can be defined and the effects of high-level risks on WG are provided.

The basic assumptions are outlined as follows:

- Each route between the WTC and the main WTC.

- Vehicle capacity could not exceed.

- Maximum distance constraint could not exceed.

- There are no initial waste quantities at the starting point.

\section{Location problem}

The first problem aims to find optimal WTC location based on the minimization of demand-weighted average distances between the hospital and the WTC, WTC and residential areas, and WTC installation costs. The notation of the mathematical modelling is presented in the following:

I, J and T define the residential area, candidate WTC nodes and time periods, respectively. $\mathrm{d}_{\mathrm{ij}}$ is the distance between the WTC nodes and the residential area. $\mathrm{M}$ is the maximum travelled distance of the vehicles. $\mathrm{C}$ is the transportation cost per $\mathrm{km}$, and B is the maximum budget to install the WTC. $\mathrm{K}_{\mathrm{j}}$ is the installation cost of WTC $\mathrm{j}$, and $\mathrm{f}$ is the operation costs of the WTC. The decision variable $y_{j}$ will be 1 if a WTC is installed at point $\mathrm{j}, 0$ otherwise. The decision variable $\mathrm{x}_{\mathrm{ij}}$ will be 1 if the residential area at point $i$ is assigned to WTC at point $j$.

Minimize

$\sum_{j=1}^{J} y_{j} K_{j}+\sum_{j=1}^{J} \sum_{i=1}^{T} f y_{j}+\sum_{i=1}^{I} \sum_{j=1}^{J} C d_{i j} x_{i j}$

The objective function (1) ensures to minimize the installation cost of WTC, operation costs of WTC and demandweighted distances between the WTC and the residential area.

$$
\begin{aligned}
& \sum_{j \in J} x_{i j}=1 \quad i \in I \\
& x_{i j} \leq y_{j} \quad \mathrm{i} \in \mathrm{I}, \mathrm{j} \in \mathrm{J} \\
& \sum_{i} x_{i i} * f \leq B \\
& x_{i j} * d_{i j} \leq M \quad \quad \mathrm{i} \in \mathrm{I}, \mathrm{j} \in \mathrm{J} \\
& y_{j}=(0,1) \quad i \in \mathrm{J} \\
& x_{i j}=(0,1) \quad i \mathrm{j} \in \mathrm{J}
\end{aligned}
$$

Constraint (2) ensures that each area is allocated to a WTC. Constraint (3) ensures that area is assigned to itself if the node is assigned as a WTC. Constraint (4) ensures to decide the WTC location based on maximum budget. Constraint (5) ensures the distances between WTC and nodes regarding maximum distance constraints. Constraints (6) and (7) describe the range of the decision variables.

\section{Pickup routing problem}

The second problem is addressed to find the pickup routes between the WTC location and residential areas regarding uncertain waste amount. The notation of the mathematical modelling is presented in the following:

\section{Indices}

i: Residential area.

$\mathrm{j}$ : WTC.

l: Waste pickup nodes.

$\mathrm{k}$ : Vehicles.

\section{Parameters}

$\mathrm{c}_{\mathrm{ij}}$ : Generalized distances between nodes $\mathrm{i}$ and $\mathrm{j}$.

$\mathrm{Q}_{\mathrm{k}}$ : Capacity of vehicle $\mathrm{k}$.

$\mathrm{P}_{\mathrm{i}}$ : Waste amounts at node $\mathrm{i}$.

\section{Decision Variables}

$U_{i k}$ : upper waste limit of node i with vehicle k (unit)

$X_{i j k}=\left\{\begin{array}{l}1, \text { ifkvehiclegoestonodejfromnodei } \\ 0, \text { otherwise }\end{array}\right.$

$z_{i k}=\left\{\begin{array}{l}1, \text { if } k \text { vehicle picks up from the node } \mathrm{i} \\ 0, \text { otherwise }\end{array}\right.$

$\min \mathrm{z}=\sum_{\mathrm{k}=1}^{\mathrm{K}} \sum_{\mathrm{i}=1}^{\mathrm{I}} \sum_{\mathrm{j}=1}^{\mathrm{J}} \mathrm{c}_{\mathrm{ij}} \mathrm{X}_{\mathrm{ijk}}$

$\sum_{j=1}^{J} X_{i j k}=\sum_{j=1}^{J} X_{j i k} \quad i=1, \ldots, I ; k=1, \ldots \ldots K$

$\sum_{\mathrm{k}=1}^{\mathrm{K}} \sum_{\mathrm{j}=0}^{\mathrm{J}} \mathrm{X}_{\mathrm{ljk}}=11=1, \ldots . . \mathrm{L}$ 
$0 \leq U_{i j} \leq Q_{k} \mathrm{i}=1, \ldots ., \mathrm{I} ; \mathrm{k}=1, \ldots \ldots \mathrm{K}$

$U_{l k} \geq U_{i k}+p_{l} * z_{l k}-\left(1-X_{i j k}\right) * Q_{k} \mathrm{i}=0$,

$\ldots \mathrm{I}, 1=1, \ldots \mathrm{L} ; \mathrm{k}=1, \ldots \mathrm{K}$

$\sum_{\mathrm{j}=1}^{\mathrm{J}} \mathrm{X}_{\mathrm{jlk}} \leq z_{l k} \quad \mathrm{l}=1, \ldots \mathrm{L} ; \mathrm{j}=0, \ldots \mathrm{J} ; \mathrm{k}=1, \ldots \mathrm{K}$

$\sum_{\mathrm{i}=1}^{\mathrm{I}} \mathrm{T}_{\mathrm{ilk}} * p_{l} \leq Q_{k} \mathrm{i}=0, \ldots \mathrm{I}, \mathrm{l}=1, \ldots \mathrm{L} ; \mathrm{k}=1, \ldots \mathrm{K}$

$X_{i j k}, z_{i k}, U_{i k} \geq 0 \quad \mathrm{i}=0, \ldots \mathrm{I}, ; \mathrm{j}=0, \ldots \mathrm{J} ; \mathrm{k}=1, \ldots \mathrm{K}$

The objective function (8) minimizes the total distances between the WTC and residential area. Constraint (9) ensures that vehicle ends the tour in the WTC. Constraint (10) presents that each pickup node is visited. Constraint (11) provides that the picked-up waste amounts could not exceed the vehicle capacity. Constraint (12) and Constraint (13) allow balancing the pickup amounts. Constraint (12) calculates the transported waste amount from the residential area. Constraint (13) ensures that the vehicle pickup waste if the vehicle travels between pickup nodes. Constraint (14) ensures that the vehicle capacity could not be exceeded. Constraint (15) provides that decision variables are greater than zero point.

\section{Jimenez method}

The method is developed for fuzzy model parameters, and objective values are ranked by a fuzzy ranking method (Jimenez et al. 2007). A novelty for the method is that coefficients are demonstrated with fuzzy numbers (Hatami-Marbini and Tavana 2011). Expected value (EV) is provided with the fuzzy numbers, and $\mathrm{c}=\mathrm{c}^{\mathrm{r}}, \mathrm{c}^{\mathrm{q}}, \mathrm{c}^{\mathrm{s}}$ are predicted with optimistic, realistic and pessimistic scenario (Fathollahi-Fard et al. 2020).

$\mathrm{EV}(\mathrm{c})=\frac{\mathrm{c}^{r}+2 \mathrm{c}^{q}+\mathrm{c}^{s}}{4}$

The constraints (i.e. $\mathrm{a}=\mathrm{a}^{r}, \mathrm{a}^{q}, \mathrm{a}^{s}, \mathrm{~b}=\mathrm{b}^{r}, \mathrm{~b}^{q}, \mathrm{~b}^{s}, \mathrm{a}_{i} X \geq$ $\left.\mathrm{b}_{i}, i=1,2, \ldots ; I\right)$ are presented in the following: $(\alpha=$ feasibility level).

$\left(\alpha \frac{a_{i}^{s}+a_{i}^{q}}{2}+(1-\alpha) \frac{a_{i}^{r}+a_{i}^{q}}{2}\right) X \geq\left(\alpha \frac{b_{i}^{s}+b_{i}^{q}}{2}+(1-\alpha) \frac{b_{i}^{r}+b_{i}^{q}}{2}\right)$

$\left(\left(1-\frac{\alpha}{2}\right) \times \frac{a_{i}^{s}+a_{i}^{q}}{2}+\left(\frac{\alpha}{2}\right) \times \frac{a_{i}^{r}+a_{i}^{q}}{2}\right) \mathrm{X} \geq\left(\left(1-\frac{\alpha}{2}\right) \times \frac{b_{i}^{s}+b_{i}^{q}}{2}+\left(\frac{\alpha}{2}\right) \times \frac{b_{i}^{r}+b_{i}^{q}}{2}\right)$

Notation and formulation are described in the following: $p_{i}^{r}$ Optimistic option for waste amount on node $\mathrm{i}$. $p_{i}^{q}$ Realistic option for waste amount on node i.

$p_{i}^{s}$ Pessimistic option for waste amount on node i

$U_{l k} \geq U_{i k}+\left(\left(\frac{\alpha}{2}\right) \times \frac{p_{l}^{s}+p_{l}^{q}}{2}+\left(1-\frac{\alpha}{2}\right) \times \frac{p_{l}^{r}+p_{l}^{q}}{2}\right) * z_{l k}$

$-(\mathrm{i}=0, \ldots \mathrm{I}, \mathrm{l}=1, \ldots \mathrm{L} ; \mathrm{k}=1, \ldots \mathrm{K})$

$(1-x) * Q_{k}$

$\sum_{\mathrm{i}=1}^{\mathrm{I}} \mathrm{T}_{\mathrm{i} / \mathrm{k}} *\left(\left(\frac{\alpha}{2}\right) \times \frac{p_{l}^{s}+p_{l}^{q}}{2}+\left(1-\frac{\alpha}{2}\right) \times \frac{p_{l}^{r}+p_{l}^{q}}{2}\right)$

$(1=1, \ldots \mathrm{L} ; \mathrm{k}=1, \ldots \mathrm{K}) \leq Q_{k}$

Fuzzy parameters are included into Eqs. $(12,14)$. Feasibility degrees are presented with $\mathrm{M}=(0.4,0.5,0.6,0.7,0.8$, $0.9,1)$ (Jimenez et al. 2007).

\section{WG problem}

PPE predictions using logical models are suggested by WHO (2020). Data utilized in the pandemic disasters could be predicted using forecasting techniques (Göçmen, 2020). In this stage, WG is obtained utilizing WG formulation and time series analysis. First, WG formulation is used to find the WG. Thus, the environmental risks and operational risks are considered to incorporate to the model depicted in Table 2. The risk management covers the risk definition, measurement, evaluation and control of prioritized risks. Probability and the effect are the main parameters of risk formulation. The measurement of the probability and effects is taken by quantitative and qualitative definitions utilizing historical data and risk reports. Risk scores are obtained multiplying effect and probability parameters to prioritize risks. Risk scores are calculated to determine the risk classes between A and E in the L-type (5X5) matrix depicted in Fig. 2. High and very high classes are represented with red colour; low classes that can be neglected to control actions are depicted with green colour.

The amount of generated waste is influenced by some parameters such as population, infection rate, mortality rate, disposal practice and recyclability. Probability and severity values are assigned considering the medical waste studies. In these studies, population, infection, mortality and recov- ery rates are mainly incorporated into the risk management approaches. 
Table 2 Risk scores and classes

\begin{tabular}{llllll}
\hline & Risks & Probability & Severity & Class & Risk \\
\hline Environmental risks & High infection rate & 5 & 5 & E & 25 \\
& Increasing population & 5 & 4 & E & 20 \\
& Mortality rate & 4 & 4 & D & 16 \\
& Recovery rate & 4 & 4 & D & 16 \\
& PPE costs & 3 & 3 & C & 9 \\
& Low recyclability rate of PPE & 5 & 3 & E & 15 \\
& High disposal costs & 3 & 3 & C & 9 \\
& High maintenance costs & 3 & 2 & C & 6 \\
& Lack of waste workers & 3 & 3 & C & 9 \\
& Lack of control in waste WTCs & 3 & 4 & C & 12 \\
& Insufficient budget for waste measures & 3 & 3 & C & 9 \\
\hline
\end{tabular}

Fig. $25 \times 5$ Matrix (Peeters and Peng 2015)

\section{Likelihood}

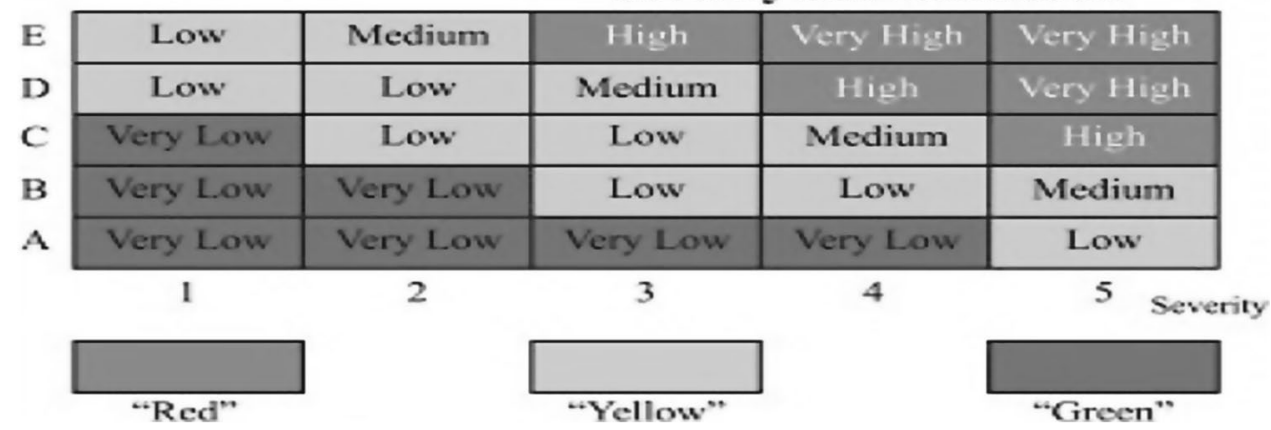

The main aims decided by the developed model are presented in the following:

- Determining the amount of generated waste for medical facilities

- Determining the amount of generated waste for residential area

A set of hospitals, in which main WTC is represented by point 0 , serve patients for a planning horizon. Hospital is denoted with $\mathrm{N}$, and time with $\mathrm{T}$.

The notations are presented in the following. The motivation of this formulation is Kargar et al. (2020).

Indices:

$t$ Period

Parameters:

PopPopulation

$I_{t}$ Infection rate in period $\mathrm{t}$

$P_{t}$ Patient rate in hospitals i in period $t$
$R_{t}$ Recovery rate in period $\mathrm{t}$

$\operatorname{Rec}_{t}$ Recyclability rate in period $\mathrm{t}$

$M_{t}$ Mortality rate in period $\mathrm{t}$

$Q_{t}$ Number of patients quarantined in period t

$H_{t}$ Patient rate getting hospitalized in period $\mathrm{t}$

$W_{t}$ Waste amount in period $\mathrm{t}$

$W G H_{t}=\left(\left(P o p * I_{t} * P_{t} * H_{t}\right)+\left(1-R_{t}-M_{t}-\operatorname{Rec}_{t}\right)\right) * W_{t}$

$W G R_{t}=\left(\left(P o p * I_{t} * P_{t} * H_{t}\right)+\left(Q_{t} *\left(1-R_{t}-\operatorname{Rec}_{t}\right)\right) * W_{t}\right.$

Equations (1-2) are waste generation formulations that waste at each period is calculated by considering the parameters. The data including observed medical waste amount between 2009 and 2019 are also used to predict the 2020 value. Figure 3 shows the Holt-Winters model. $S_{t}$ and $T_{t}$ are level and additive trends. Smoothing symbols are $\alpha$ and 


$$
\begin{gathered}
S_{t}=\alpha\left(\frac{X_{t}}{I_{t-s}}\right)+(1-\alpha)\left(S_{t-1}+T_{t-1}\right) \\
T_{t}=\gamma\left(S_{t}-S_{t-1}\right)+(1-\gamma) T_{t-1} \\
I_{t}=\delta\left(\frac{X_{t}}{S_{t}}\right)+(1-\delta) I_{t-s} \\
\widehat{X}_{t+h}=\left(S_{t}+h T_{t}\right) I_{t-s+h}
\end{gathered}
$$

Fig. 3 Holt-Winters model (Trull et al. 2020)

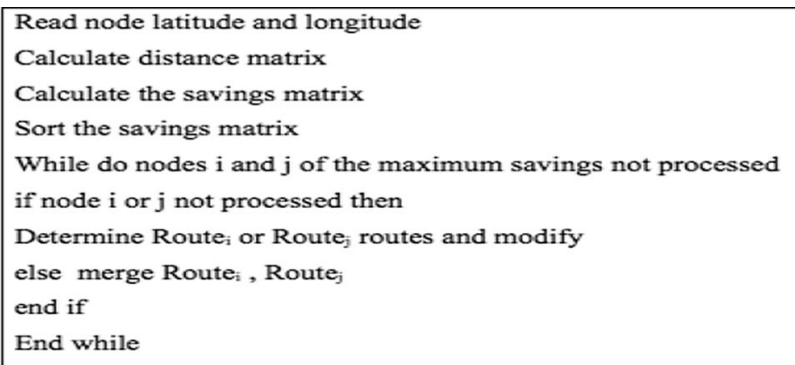

Fig. 4 Pseudocode for PRP

external loop as stop criterion. Metropolis probability formulation is used when the solution in the current iteration is not better than the before. This formulation is defined in the following: Metropolis possibility $=\mathrm{e}-(\mathrm{f}(\mathrm{xi})-\mathrm{f}(\mathrm{xi}-1)) /\left(\mathrm{kb}^{*} \mathrm{~T}\right), *$ Boltzmann sabiti $k b=1,380,650,524.10-23 \mathrm{~J} / \mathrm{K}$. xi starting point $(\mathrm{i}=0)$, $\mathrm{f}(\mathrm{xi})$ is calculated. $\mathrm{f}(\mathrm{xi}-1)$ is obtained with $\mathrm{xi}=\mathrm{xi}-1$.

- After each calculation step, the temperature is mitigated based on a specified function.

- The algorithm is finished when the expected iteration is obtained, or the temperature obtains the minimum value. SA parameters used are as follows:

$\mathrm{I}_{\text {iter, }}$, maximum iteration is 100 ; maximum inner iteration is $10 ; \mathrm{T}_{0}$, initial temperature is 100 ;

$\alpha$, temperature damping rate is 0.98 .

Simulated annealing is applied for the PRP. A modified savings is defined, and the pseudocode is depicted in Fig. 4. The node latitude and longitude values (mainly $\left.39^{0}, 39^{0}\right)$ are used.

\section{Case study}

To evaluate the developed model to control the pandemic supply chain, a real case is presented. The required data to conduct this study are obtained from Tunceli City located in Turkey. WTC is not available in this city, the pickup waste amounts are transported to the other city, named Bingöl in Turkey. In this problem, various candidate locations are considered as WTC. The waste in each residential area is transported to WTC. The total population of Tunceli is 84660 . To calculate the waste included by WTC, a weight linked with the historical data of WG amount is assigned. Distances between residential area and WTC are measured using Google Maps. Table 3 demonstrates the distance matrix between the WTC and districts, represented as nodes in the paper. 
Table 3 Distance matrix

\begin{tabular}{lllllllll}
\hline & Node 1 & Node 2 & Node 3 & Node 4 & Node 5 & Node 6 & Node 7 & Node 8 \\
\hline Node 1 & 0 & 55,8 & 57,8 & 43,9 & 74,1 & 70,3 & 122 & 44,4 \\
Node 2 & 55,8 & 0 & 42 & 80 & 111 & 80,8 & 66,7 & 49 \\
Node 3 & 57.8 & 42 & 0 & 82,2 & 112 & 67,4 & 59,9 & 58,8 \\
Node 4 & 43,9 & 80 & 82,2 & 0 & 55,2 & 94,7 & 146 & 68,8 \\
Node 5 & 74,1 & 111 & 112 & 55,2 & 0 & 125 & 176 & 99,1 \\
Node 6 & 70,3 & 80,8 & 67,4 & 94,7 & 125 & 0 & 98,6 & 93,8 \\
Node 7 & 122 & 66,7 & 59,9 & 146 & 176 & 98,6 & 0 & 115 \\
Node 8 & 44,4 & 49 & 58,8 & 68,8 & 99,1 & 93,8 & 115 & 0 \\
\hline
\end{tabular}

Table 4 The location results

\begin{tabular}{llll}
\hline Distance & $\begin{array}{l}\text { Number of } \\
\text { WTC }\end{array}$ & $\begin{array}{l}\text { Number of } \\
\text { vehicles }\end{array}$ & Total cost (US dollars $\left.\times 10^{2}\right)$ \\
\hline 20 & 5 & $3-2-1$ & $15,600-14,740-13,360$ \\
40 & 4 & $3-2-1$ & $14,320-13,256-12,490$ \\
60 & 3 & $3-2-1$ & $12,200-11,560-10,420$ \\
80 & 2 & $3-2-1$ & $9980-8740-7890$ \\
100 & 1 & $3-2-1$ & $6931-6024-5982$ \\
\hline
\end{tabular}

\section{Results and discussion}

Computational analysis is provided for the utilization of the presented method. The MIP could solve the location problem a reasonable time. The heuristics are provided to solve the PRP. To handle the fuzzy parameters, Jimenez method is included to the PRP. Optimistic, realistic and pessimistic scenarios are obtained from the prediction method and WG formulation.

\section{Location and PRP results}

Developed mathematical models are tested on the case study. In addition, sensitivity analysis is provided for the model verification and to analyse the parameter changes. In this analysis, location results and total costs utilizing MIP solver are demonstrated in Table 4. Total cost is computed for each distance, number of vehicles and WTC. The results show that total cost increases with the number of vehicles and WTC. At the distance constraint for 20-100 km, changes on the total cost, number of WTC and vehicles are investigated. One WTC is required to cover all area within $100 \mathrm{~km}$ since the city is not enough large and installation of the second WTC is costly. $125-150 \mathrm{~km}$ restrictions are not more influential on the total cost.

In Table 5, routes and waste quantities for each node are obtained using MIP solver. The total waste obtained is
Table 5 Waste quantities for vehicles

\begin{tabular}{llll}
\hline Nodes/vehicles & $\begin{array}{l}\text { Vehicle 1 } \\
\text { (tonne) }\end{array}$ & $\begin{array}{l}\text { Vehicle 2 } \\
\text { (tonne) }\end{array}$ & Vehicle 3 (tonne) \\
\hline Node 1 & & 90,000 & \\
Node 2 & 2300 & 1500 & \\
Node 3 & & & \\
Node 4 & 1200 & & 1400 \\
Node 5 & & & 1800 \\
Node 6 & & 400 & 232 \\
Node 7 & & & \\
Node 8 & & & \\
\hline
\end{tabular}

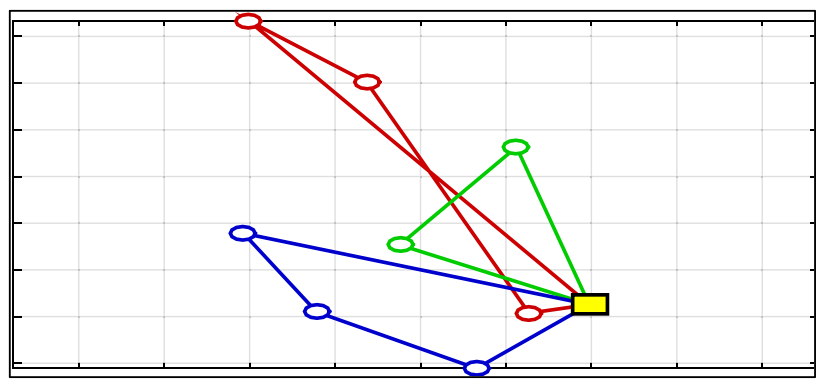

Fig. 5 Routes developed by SA code

shared to the nodes based on the population and density. The starting and end point of the routes is WTC. Routes are generated for the pickup process regarding capacity of the vehicles and the amount of the waste and presented in the following: Vehicle 1 follows the route as WTC-2-4WTC, Vehicle 2 follows the route as WTC-1-3-7-WTC, and Vehicle 3 follows the route as WTC-6-8-5-WTC.

In SA, the same routes are generated. Figure 5 depicts that those three routes are formed regarding latitude and longitude. Comparing MIP solver, same routes are generated. Green line represents the first tour, while the second and third routes are represented by red and blue lines, respectively. Yellow symbol depicts the installed WTC.

Vehicle 1 follows this route: WTC-Node 2-Node 4-WTC 
Vehicle 2 follows this route: WTC-Node 1-Node 3-Node 7-WTC

Vehicle 3 follows this route: WTC-Node 6-Node 8-Node 5-WTC.

Figure 6 demonstrates the routing cost for each iteration. The algorithm is finished when maximum iteration 100 is obtained. The results show that the routing cost is obtained as 422,200 US Dollars. MIP solver provides the same cost under the feasibility level 0.4 depicted in Table 3 . With iteration 15 , the routing cost is accepted as new solution.

Computational results including location and routing costs are provided in Table 6 . Sensitivity analysis is also provided for the model verification and to evaluate the degree changes. The minimum total cost is obtained under the feasibility level 0.4 .

\section{WG results}

In the WG formulation, high-level risks (15-20 scores) depicted in Table 7 are incorporated into the equations. High infection rate and population are the most influential factors on WG. In the presented paper, residential areas with high infection rate and population produces more waste.

WG rate in hospitals and residential area is about $1.2 \mathrm{~kg}$ per patient and day. The total population is 84660 . Infection rate is considered 0.77 as low estimate. Recovery and recycling rate is only $3 \%$ for polypropylene PPE (Singh et al., 2020a,b). Mortality rate and recovery rate are $\% 1.9$ and $\% 55.2$, respectively. Thus, WG for hospital and for residential area is obtained as 39,521 and 40,131 ton, respectively.

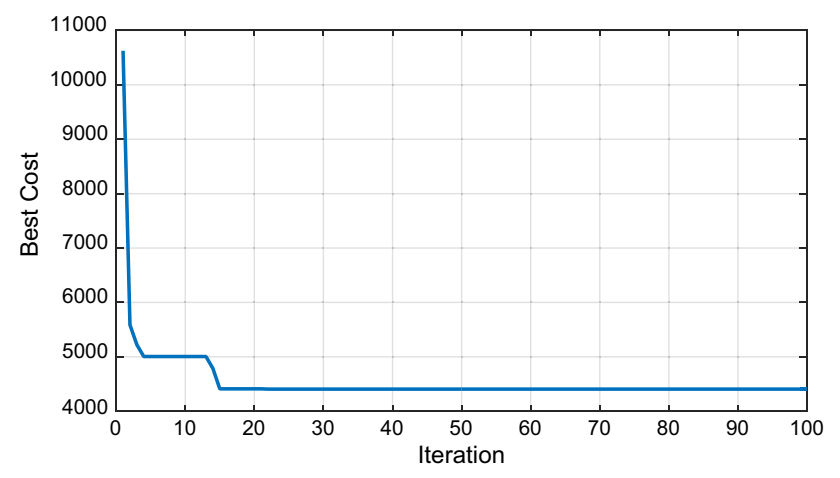

Fig. 6 Cost solutions $\left(10^{2} \times\right.$ US Dollars $)$ of iterations
Total value nearly 79,652 ton is used to obtain the optimistic scenario.

Risk response strategies are carried out for the high-level risks. The European waste hierarchy presents six methods in the following:

Prevention: The most favourable option is prevention in the waste hierarchy. The WFD 2008 defines this term as measures to reduce the amount of waste (Gharfalkar et al. 2015).

Minimization: Minimization of waste brings about cost savings, challenging business areas (UNEP 2011).

Reuse: This term means that using waste in their original form with little repair.

Recycle: Recycle includes reprocessing waste to produce new material.

Recovery: Recovery defines the energy produced from waste.

Disposal: Disposal of infectious medical wastes is challenging that WHO states an environmentally friendly and low-cost method for infectious medical wastes (Birchard 2002).

Then, WG is generated by utilizing the Holt-Winters method. Table 8 demonstrates the predicted waste amount based on the base level, trend and seasonal factors to obtain the pessimistic scenario. This value is used for the pessimistic number in Jimenez method. Realistic scenario is considered as the average of the optimistic and pessimistic values, 89,242 ton.

In order to compare the performance of the prediction, the linear regression model is provided, and the linear regression equation is provided in the following formula:

$\mathrm{WG}=80,801-0.017 *$ population $+44.268 *$ number of patients $+1.708 *$ number of beds $-1.331 *$ number of doctors $+0.080 *$ number of deaths. The linear regression results are demonstrated in Table 9. The result ensures a correlation which can predict the number of medical wastes as a function of city population, the number of patients, the

Table 7 High-level risks

\begin{tabular}{lllll}
\hline Risk & Probability & Severity & Class & Risk \\
\hline High infection rate & 5 & 5 & E & 25 \\
Increasing population & 5 & 4 & E & 20 \\
Mortality rate & 4 & 4 & D & 16 \\
Recovery rate & 4 & 4 & D & 16 \\
Low recyclability rate of PPE & 5 & 3 & E & 15 \\
\hline
\end{tabular}

Table 6 Objective function results

\begin{tabular}{llllllll}
\hline Feasibility levels $\alpha$ & 0.4 & 0.5 & 0.6 & 0.7 & 0.8 & 0.9 & 1 \\
Routing cost $\left(\right.$ US Dollars $\times 10^{2}$ ) & 4222 & 4227 & 4545 & 4401 & 4368 & 4384 & 4384 \\
Location cost $\left(\right.$ US Dollars $\times 10^{2}$ ) & 2709 & 4334 & 4678 & 4980 & 5025 & 5213 & 5223 \\
\hline
\end{tabular}


Table 8 Prediction results of medical waste amount

\begin{tabular}{lllllll}
\hline Year & $\begin{array}{l}\text { Time } \\
\text { period }(\mathrm{t})\end{array}$ & $\begin{array}{l}\text { Observed medical waste } \\
\text { amount (tonne) }\left(\mathrm{X}_{\mathrm{t}}\right)\end{array}$ & Base level $\left(\mathrm{S}_{\mathrm{t})}\right.$ & Trend $\left(\mathrm{T}_{\mathrm{t}}\right)$ & $\begin{array}{l}\text { Seasonal } \\
\text { factor }\left(\mathrm{I}_{\mathrm{t}}\right)\end{array}$ & $\begin{array}{l}\text { Predicted waste } \\
\text { amount (tonne) }\end{array}$ \\
\hline 2009 & 1 & 29,4 & - & - & 0,942 & - \\
2010 & 2 & 28,02 & - & - & 0,898 & - \\
2011 & 3 & 24,9 & - & - & 0,798 & - \\
2012 & 4 & 42,54 & 31,2 & 0,0 & 1,363 & - \\
2013 & 5 & 43,22 & 31,2 & 0,0 & 1,163 & 42,540 \\
2014 & 6 & 74,52 & 31,2 & 0,0 & 1,642 & 36,310 \\
2015 & 7 & 248,396 & 31,2 & 0,0 & 4,378 & 51,270 \\
2016 & 8 & 52,85 & 31,2 & 0,0 & 1,528 & 136,648 \\
2017 & 9 & 52,654 & 31,2 & 0,0 & 1,425 & 47,695 \\
2018 & 10 & 54,778 & 31,2 & 0,0 & 1,699 & 44,482 \\
2019 & 11 & 61,015 & 31,2 & 0,0 & 3,166 & 53,024 \\
2020 & 12 & - & 31,2 & 0,0 & 0,764 & 98,832 \\
\hline
\end{tabular}

Table 9 Linear regression results

\begin{tabular}{lllllll}
\hline Model & Sum of squares & Df & Mean square & F & Sig & $\mathrm{R}^{2}$ \\
\hline Regression & 7731.109 & 5 & 1546.222 & 39.190 & 0,000 & 0.894 \\
\hline
\end{tabular}

number of hospital beds, doctors and deaths (significance value $\left.0.000<0.05, \mathrm{R}^{2}=0.894\right)$.

\section{Conclusion}

Increasing demand of PPE has been controlled all over the world. Thus, providing an IPPE management is necessity to deal with this problem. In this regard, PPE waste planning for a city supply chain problem is conducted considering WTC location and routing decisions. The presented model ensures both distribution and location decisions, and WG prediction utilizing both mathematical formulation and prediction method. In addition, a risk management approach is developed to handle the environmental and operational risk factors to decide the WG. The computational results on real case data illustrate that integrated waste management approach could be effective to prevent the waste and provide more healthy people and sustainable world. To summarize the paper, IPPE management under uncertain environment is addressed. Uncertain parameters are assigned considering optimistic, realistic and pessimistic scenarios of Jimenez method. HW model and WG formulation is also used to assign these scenarios. For WG formulation, risk factors on IPPE WG are examined.

In recent years, integrating health and sustainability applications have attracted considerable attention. Environment-based methods are of vital importance for the decision-makers to revise the traditional systems. Effective waste techniques are crucial to decide whether the decision-makers take into account the global world requirements. Smart medical waste disposal applications are the backbone of the sustainable world. Since world population and illnesses dramatically increase, ecosystem balance must be ensured. To deal with these issues, waste management systems should be examined, measured and analysed. Using new technologies is required since large data are utilized. For future works, stochastic programming modelling is suggested for IPPE waste logistics. Moreover, incorporating traffic loads of obtained routes can ensure more realistic solution to the problem. The limitation of this paper is that SA method may not be applicable for more populated cities, 1 million above.

Decision-making methods are focal stage to solve some problems such as selection of waste treatment methods. These problems are more complex since methods have some similarities, e.g. recovery, recycling and reuse. Therefore, decision-makers can fail to determine the methods and obtain mistaken results. An automated computational system is required to achieve to detect the optimum method.

Managerial views for medical sector regarding computational results are listed as follows:

- Important issue to prevent the IPPE waste is an optimal prediction of waste amount. Hence, real data could provide decision-makers to define the waste levels.

- For large-scale networks, integrated waste management plans are required to develop the network. Installing waste centres, waste picking decisions and waste generation plans should be handled. 
Acknowledgements This study did not receive any funding, and there is no conflict of interest (financial or non-financial). The author thanks Tunceli Provincial Directorate of Environment and Urbanization for providing the data presented. The authors thank all who assisted in conducting this work.

\section{Declarations}

Conflict of interest There is no conflict of interest.

Human and animal rights This article does not contain any studies with human participants or animals performed by any of the authors.

\section{References}

Adyel TM (2020) Accumulation of plastic waste during COVID-19. Sci 369:1314-1315. https://doi.org/10.1126/science.abd9925

Archetti C, Bertazzi L, Laporte G, Speranza MG (2007) A branch-andcut algorithm for a vendor-managed inventory-routing problem. Transport sci 41(3):382-391. https://doi.org/10.1287/trsc.1060. 0188

Birchard K (2002) Out of sight, out of mind... the medical waste problem. The Lancet 359(9300):56. https://doi.org/10.1016/ S0140-6736(02)07256-2

Budak A, Ustundag A (2017) Reverse logistics optimisation for waste collection and disposal in health institutions: the case of Turkey. Int J Log Res and App 20(4):322-341. https://doi.org/ $10.1080 / 13675567.2016 .1234595$

Chauhan A, Singh A (2016) A hybrid multi-criteria decision making method approach for selecting a sustainable location of healthcare waste disposal facility. J Clean Prod 139:1001-1010. https://doi.org/10.1016/j.jclepro.2016.08.098

Cook TM (2020) Personal protective equipment during the coronavirus disease (COVID) 2019 pandemic a narrative review. Anaesthesia. https://doi.org/10.1111/anae.15071

Dargaville T, Spann K, Celina M (2020) Opinion to address a potential personal protective equipment shortage in the global community during the COVID-19 outbreak. Poly Degra Stab. 176:109162. https://doi.org/10.1016/j.polymdegradstab.2020. 109162

Dursun M, Karsak EE, Karadayi MA (2011) Assessment of healthcare waste treatment alternatives using fuzzy multi-criteria decision making approaches. Res Conserv Recy 57:98-107. https:// doi.org/10.1016/j.resconrec.2011.09.012

Fadare OO, Okoffo ED (2020) Covid-19 face masks: A potential source of microplastic fibers in the environment. Sci Total Environ 737:140279. https://doi.org/10.1016/j.scitotenv.2020.140279

Fathollahi-Fard AM, Ahmadi A, Goodarzian F, Cheikhrouhou N (2020) A bi-objective home healthcare routing and scheduling problem considering patients' satisfaction in a fuzzy environment. App Soft Comp 93:106385. https://doi.org/10.1016/j. asoc.2020.106385

Gergin Z, Tunçbilek N, Esnaf Ş (2019) Clustering approach using artificial bee colony algorithm for healthcare waste disposal facility location problem. Int J Op Res Info Sys 10(1):56-75. https://doi.org/10.4018/IJORIS.2019010104

Gharfalkar M, Court R, Campbell C, Ali Z, Hillier G (2015) Analysis of waste hierarchy in the European waste directive 2008/98/EC. Waste Manag 39:305-313. https://doi.org/10.1016/j.wasman. 2015.02.007

Göçmen E (2020) Linear programming with fuzzy parameters for inventory routing problem in effective management of personal protective equipment: a case study of corona virus disease 2019. Energy Sources Part A Rec, Util, and Environ Effects. https://doi. org/10.1080/15567036.2020.1861133

Govindan K, Mina H, Alavi B (2020) A decision support system for demand management in healthcare supply chains considering the epidemic outbreaks: a case study of coronavirus disease 2019 (COVID-19). Transp Res Part E: Logis Transp Rev 138:101967. https://doi.org/10.1016/j.tre.2020.101967

Haque MS, Uddin S, Sayem SM, Mohib KM (2020) Coronavirus disease 2019 (COVID-19) induced waste scenario: A short overview. J Environ Chem Eng. https://doi.org/10.1016/j.jece.2020.104660

Hatami-Marbini A, Tavana M (2011) An extension of the linear programming method with fuzzy parameters. Int J Math Op Res 3(1):44-55. https://doi.org/10.1504/IJMOR.2011.037312

Iglesias A, del Castillo MD, Santos M, Serrano JI, Oliva I (2008) A comparison between possibility and probability in multiple criteria decision making. Comp Intel Dec Cont. https://doi.org/10. 1142/9789812799470_0050

Ilyas S, Srivastava RR, Kim H (2020) Disinfection technology and strategies for COVID-19 hospital and bio-medical waste management. Sci Total Environ 749:141652. https://doi.org/10.1016/j. scitotenv.2020.141652

Imran M, Salman Habib M, Hussain A, Ahmed N, Al-Ahmari MA (2020) Inventory routing problem in supply chain of perishable products under cost uncertainty. Math 8(3):382. https://doi.org/ $10.3390 /$ math 8030382

Jiménez M, Arenas M, Bilbao A, Rodrı MV (2007) Linear programming with fuzzy parameters: an interactive method resolution. Euro J Opl Res 177(3):1599-1609. https://doi.org/10.1016/j.ejor. 2005.10.002

Ju Y, Liang Y, Luis M, Gonzalez EDS, Giannakis M, Dong P, Wang A (2020) A new framework for health-care waste disposal alternative selection under multi-granular linguistic distribution assessment environment. Comp Industr Eng 145:106489. https://doi.org/ 10.1016/j.cie.2020.106489

Kargar S, Pourmehdi M, Paydar MM (2020) Reverse logistics network design for medical waste management in the epidemic outbreak of the novel coronavirus (COVID-19). Sci Total Environ 746:141183. https://doi.org/10.1016/j.scitotenv.2020.141183

Korkut EN (2018) Estimations and analysis of medical waste amounts in the city of Istanbul and proposing a new approach for the estimation of future medical waste amounts. Waste Manag 81:168 176. https://doi.org/10.1016/j.wasman.2018.10.004

Lee BK, Ellenbecker MJ, Moure-Ersaso R (2004) Alternatives for treatment and disposal cost reduction of regulated medical wastes. Waste Manag 24(2):143-151. https://doi.org/10.1016/j.wasman. 2003.10.008

Liu HC, Wu J, Li P (2013) Assessment of health-care waste disposal methods using a vikor-based fuzzy multi-criteria decision making method. Waste Manag 33(12):2744-2751. https://doi.org/10. 1016/j.wasman.2013.08.006

Liu HC, You JX, Lu C, Chen YZ (2015) Evaluating health-care waste treatment technologies using a hybrid multi-criteria decision making model. Renew Sust Energy Rev 41:932-942. https://doi.org/ 10.1016/j.rser.2014.08.061

Liu Z, Li Z, Chen W, Zhao Y, Yue H, Wu Z (2020) Path optimization of medical waste transport routes in the emergent public health event of Covid-19: a hybrid optimization algorithm based on the immune-ant colony algorithm. Int J Environ Res Pub Health 17(16):5831. https://doi.org/10.3390/ijerph17165831

Makajic-Nikolic D, Petrovic N, Belic A, Rokvic M, Radakovic JA, Tubic V (2016) The fault tree analysis of infectious medical waste management. J Clean Prod 113:365-373. https://doi.org/ 10.1016/j.jclepro.2015.11.022

Mantzaras G, Voudrias EA (2017) An optimization model for collection, haul, transfer, treatment and disposal of infectious medical 
waste: application to a greek region. Waste Manag 69:518-534. https://doi.org/10.1016/j.wasman.2017.08.037

Mishra AR, Mardani A, Rani P, Zavadskas EK (2020) A novel EDAS approach on intuitionistic fuzzy set for assessment of health-care waste disposal technology using new parametric divergence measures. J Clean Prod 272:122807. https://doi.org/10.1016/j.jclepro. 2020.122807

Nolz PC, Absi N, Feillet D (2014) A stochastic inventory routing problem for infectious medical waste collection. Networks 63(1):8295. https://doi.org/10.1002/net.21523

Nzediegwu C, Chang SX (2020) Improper solid waste management increases potential for COVID-19 spread in developing countries. Res Conserv Recy. 161:104947

Peeters W, Peng Z (2015) An approach towards global standardization of the risk matrix. J Space Safety Eng 2(1):31-38. https://doi.org/ 10.1016/j.resconrec.2020.104947

Penteado CSG, de Castro MAS (2020) Covid-19 effects on municipal solid waste management: What can effectively be done in the Brazilian scenario? Res Conserv Recy. 164:105152. https://doi.org/ 10.1016/j.resconrec.2020.105152

Pincus M (1970) Letter to the editor- a Monte Carlo method for the approximate solution of certain types of constrained optimization problems. Op Res 18(6):1225-1228. https://doi.org/10.1287/opre. 18.6.1225

Rhee SW (2020) Management of used personal protective equipment and wastes related to COVID-19 in South Korea. Waste Manag Res. https://doi.org/10.1177/0734242X20933343

Singh N, Tang Y, Zhang Z, Zheng C (2020a) COVID-19 waste management: Effective and successful measures in Wuhan. China Res Conserv Recy 163:105071. https://doi.org/10.1016/j.resconrec. 2020.105071

Singh N, Tang Y, Ogunseitan OA (2020b) Environmentally sustainable management of used personal protective equipment. Environ Sci Technol 54(14):8500-8502. https://doi.org/10.1021/acs.est. 0c03022

Trull Ó, García-Díaz JC, Troncoso A (2020) Stability of multiple seasonal holt-winters models applied to hourly electricity demand in Spain. App Sci 10(7):2630. https://doi.org/10.3390/app10072630

UNEP 2011. Decoupling natural resource use and environmental impacts from economic growth. united nations environment programme, Paris.
Van Fan Y, Jiang P, Hemzal M, Klemeš JJ (2020) An update of COVID-19 influence on waste management. Sci Total Environ 754:142014. https://doi.org/10.1016/j.scitotenv.2020.142014

Wang J, Shen J, Ye D, Yan X, Zhang Y, Yang W, Pan L (2020) Disinfection technology of hospital wastes and wastewater: Suggestions for disinfection strategy during coronavirus Disease 2019 (COVID-19) pandemic in China. Environ Pollut 262:114665. https://doi.org/10.1016/j.envpol.2020.114665

World Health Organization. (2020). Rational use of personal protective equipment for coronavirus disease (COVID-19) and considerations during severe shortages: interim guidance, 6 April 2020 (No. WHO/2019-nCov/IPC_PPE_use/2020.3). World Health Organization

Xiao F (2018) A novel multi-criteria decision making method for assessing health-care waste treatment technologies based on D numbers. Eng App Artif Int 71:216-225. https://doi.org/10.1016/j. engappai.2018.03.002

Yang L, Yu X, Wu X, Wang J, Yan X, Jiang S, Chen Z (2020) Emergency response to the explosive growth of health care wastes during COVID-19 pandemic in Wuhan. China. Res Conserv Recyc 164:105074. https://doi.org/10.1016/j.resconrec.2020.105074

Yazdani M, Tavana M, Pamučar D, Chatterjee P (2020) A rough based multi-criteria evaluation method for healthcare waste disposal location decisions. Comp Indust Eng 143:106394. https://doi. org/10.1016/j.cie.2020.106394

Yu H, Sun X, Solvang WD, Zhao X (2020) Reverse logistics network design for effective management of medical waste in epidemic outbreaks: Insights from the coronavirus disease 2019 (COVID19) outbreak in Wuhan (China). Int J Environ Res Pub Health 17(5):1770. https://doi.org/10.3390/ijerph17051770

Zambrano-Monserrate MA, Ruano MA, Sanchez-Alcalde L (2020) Indirect effects of COVID-19 on the environment. Sci Total Environ 728:138813. https://doi.org/10.1016/j.scitotenv.2020.138813

Zavadskas EK, Antucheviciene J, Turskis Z, Adeli H (2016) Hybrid multiple-criteria decision-making methods: A review of applications in engineering. Scientia Iranica Transac A Civil Eng 23(1):1 